\title{
Employers' social contacts and their hiring behavior in a factorial survey
}

\author{
Valentina Di Stasio ${ }^{\mathrm{a}}$ and Klarita Gërxhani ${ }^{\mathrm{b}}$ \\ ${ }^{\mathrm{a}}$ Corresponding author \\ Department of Sociology and Amsterdam Centre for Inequality Studies \\ University of Amsterdam, \\ Nieuwe Achtergracht 166 \\ 1089 WV Amsterdam, the Netherlands \\ Email: v.distasio@uva.nl \\ Tel. 0031 (0)205253626 \\ ${ }^{\mathrm{b}}$ Department of Sociology and Amsterdam Centre for Inequality Studies \\ University of Amsterdam, \\ Nieuwe Achtergracht 166 \\ 1089 WV Amsterdam, the Netherlands \\ Email: k.gerxhani@uva.nl
}

\begin{abstract}
In this study, we investigate whether referrals from employers' business and professional contacts matter in the hiring process. Additionally, we examine whether the effect of this type of informal recruitment varies depending on: (1) the signaling role of education during the hiring process, and (2) applicants' level of education. Based on a combination of a factorial survey and an experimental design with a sample of employers in England, we measure the effect of referrals on employers' hiring assessments. We find only weak evidence that referred applicants are considered more trainable than otherwise identical applicants that do not have a tie with the employer. More detailed analyses show that referrals do matter for employers who consider education a noisy signal, in line with the argument that informal recruitment can represent a strategy for employers to compensate for poor signaling. Referrals are especially beneficial for highly educated applicants, probably a sign that employers need some guarantee against possible wage or turnover costs.
\end{abstract}

Keywords: employers; hiring; factorial survey; referrals; education. 


\section{Introduction}

Networks of interpersonal ties are often described as conduits for the flow of high-quality information. In particular, their role in fostering labor market opportunities has been addressed by sociological studies on the importance of social contacts in the job search (De Graaf and Flap 1988, Granovetter 1995, Lin 1999, Erikson 2001, Flap and Boxman 2001, Kmec and Trimble 2009). From a job-seeker's perspective, obtaining information from networks of interpersonal ties ${ }^{1}$ (i.e. friends, relatives, colleagues, or acquaintances) is known as informal job search. From an employer's perspective, it is known as informal recruitment.

Informal recruitment methods and informal job search activities have in common the fact that a tie conveys in-depth information about job applicants and job opportunities, respectively. However, the literature on the role of ties in the labor market has mainly considered the supply side of job matching, i.e. job-seekers, with a focus on their use of networks during the job search. Marsden and Gorman (2001) stress that interpersonal ties can also play a role in the recruitment process: specifically, employers may recruit via referrals by publicizing job openings among incumbent employees or business and professional contacts and asking them to recommend qualified applicants. Employers' reliance on referrals from incumbent employees during the recruitment process has been investigated in a number of studies which use detailed personnel records to measure the chances of referred job applicants' success at each, consecutive stage of the hiring process (Fernandez et al. 2000, Petersen et al. 2000). Findings from these studies confirm that referrals from incumbent employees increase the chances of being invited for a job interview and lead to higher job offer rates compared to non-referred applicants.

We aim to contribute to this literature by examining an important type of referral that has been under-researched, namely business and professional contacts of the employer. These are network contacts that do not originate in the firm. They can be established and 'mobilized' in gatherings of professional and branch organizations, conferences, online networks, but also in informal settings, for instance while playing golf or at a charity gathering. A few studies emphasize the importance and frequency of this type of recruitment (Petersen et al. 2000, Behrenz 2001, Marsden 2001, Pinkston 2012). In addition, the increasing impact of on-line networks, such as LinkedIn, connecting business and professional contacts raises the issue as to what is happening in the external networking world. Hence, our first research question addresses whether referrals from business and professional contacts matter for employers' hiring behavior. Theoretically, we provide various arguments as to why these contacts might matter, by referring to a set of mechanisms used in previous seminal works of Fernandez and others (e.g. Fernandez et al. 2000, Neckerman and Fernandez 2003, Fernandez and Galperin 2014) that studied referrals from incumbent employees from the perspective of employers. Empirically, we apply a combination of a factorial survey with an experimental design, allowing for a proper assessment of the effect of employers' business contacts on their hiring decisions.

\footnotetext{
${ }^{1}$ In this paper, we will use the terms interpersonal ties and social contacts interchangeably.
} 
From a methodological point of view, our study speaks directly to both Mouw's (2006) and Fernandez and Galperin's (2014) recent work on how to address issues of endogeneity when studying the role of ties in the labor market with non-experimental data: namely, wellconnected individuals may differ from individuals with few or no labor market ties on a number of unobserved characteristics that affect both their likelihood to be part of a network and their labor market outcomes. If this were the case, the effect of social ties would be spurious due to social homophily. We address this selection bias by relying on a factorial survey and an experimental manipulation, in line with Mouw's (2006: 81) call for "fairly simple methods combined with innovative use of quasi-experimental data”. A factorial survey is a regression-based technique to analyze how respondents evaluate hypothetical objects, profiles or situations that are described on vignettes (Rossi and Anderson 1982, Jasso 2006, Wallander 2009). The method is well-suited to study complex decision-making processes such as hiring. This is because, compared to other methods, in factorial surveys various attributes are varied simultaneously, limiting the risk of socially desirable answers (Wallander 2009, Mutz 2011).

In our study, we asked employers to rate a number of vignettes describing hypothetical job applicants that randomly varied along certain characteristics (e.g. gender, qualifications, previous work experience). The ratings reflect employers' perception about the likelihood that: they would hire the applicants; and the applicants, if hired, would be easy to train and fit with the corporate culture of the organization. The experimental manipulation allowed us to collect, for each employer, ratings of the same applicants under two conditions: when referred and when non-referred by business and professional contacts of the employer. By treating the latter as the counterfactual for how applicants would be assessed if not referred, we are able to cope with the fundamental challenge, stressed by Mouw (2003; 2006), of comparing referred applicants with otherwise identical applicants who cannot rely on a tie with the employer. Our focus on the demand side of the labor market also adds to an emerging literature pioneered by Fernandez and Galperin (2014) that looks at the causal effect of referrals from the employers' perspective. Compared to their study, which analyzed referrals from incumbents based on data on repeated applications in a single firm in the United States, ours has the advantage that it isolates the effect of referrals for applicants that apply for the same job opening and are screened by the same organizational agent. In addition, we focus on a different type of tie: that between the employer and a business or professional contact.

The contribution of our study goes a step further by linking this type of informal recruitment to the signaling role of education during the hiring process. Previous studies have shown that employers, despite having school-based indicators of human capital (e.g. grades, transcripts), are less inclined to use this information during the hiring process unless it is obtained from trusted channels, such as their own workers or other long-term social networks (Miller and Rosenbaum 1997, Brinton and Kariya 1998, Rosenbaum et al. 1999). Thus, these studies relate employers' use of networks in recruitment to the signaling role of education: if education does not convey clear or credible information (i.e. education is a noisy signal for 
employers), one would expect employers to rely more heavily on their social contacts. Research on recruitment also suggests that information obtained from informal recruitment channels should be even more important when formal institutions such as the education system fail to send clear signals to employers (Marsden 2001). We are not aware, however, of any study that empirically tests whether this is the case. It is thus an open question whether employers will rely more on their business and professional contacts when education is perceived as a poor signal. Moreover, it is also unknown whether employers rely on their contacts more frequently when an applicant's educational qualification is high than when it is low. Given the higher uncertainty and the expected investments related to hiring applicants with higher levels of education (Flap and Boxman 2001), employers may find some form of guarantee in their ties with their business and professional contacts.

Our study is based on unique survey data of employers' hiring behavior in England. England is a typical case of a weakly standardized education system: multiple, somewhat overlapping qualification frameworks exist, and standards with regard to the content of curricula and the organization of teacher training are lacking (Scherer 2005). As a result, one can expect variation in the way English employers perceive the signaling role of education. Our data allows us to test whether English employers who perceive education as a noisy signal, use informal recruitment channels as a compensatory strategy.

\section{Theoretical framework}

\subsection{Ties in the labor market: informal recruitment}

The extensive literature on the use of interpersonal ties has made a substantial contribution to our understanding of the workings of the labor market. Though not as exhaustive as the informal job search literature, ${ }^{2}$ the extent to which employers engage in informal recruitment when filling vacancies, and their preference for informal over formal channels, has attracted the attention of scholars from both sociology (Boxman et al. 1991, Erikson 2001, Marsden 2001, Marsden and Gomoran 2001, Gërxhani et al. 2013, Gërxhani and Koster forthcoming) and economics (Montgomery 1991, Behrenz 2001, Schram et al. 2010). Framed from the employers' perspective, one has to consider the advantage that employers can gain from the use of information that is channeled through social networks (Montgomery 1991): what matters is whether and to what extent employers rely on social ties with incumbent employees or other business contacts while making hiring decisions.

Employers' reliance on referrals from their incumbent employees has been thoroughly studied (e.g. Fernandez et al. 2000, Petersen et al. 2000, Neckerman and Fernandez 2003). Other sources of referrals, i.e. employers' own business and professional contacts, have received less attention. The few existing studies do however indicate that this type of referral may play an important role in employers' recruitment and selection decisions. On the basis of

\footnotetext{
${ }^{2}$ For some points of criticism on this literature, see Mouw (2003).
} 
data from the National Organization Study, a representative employer survey in the United States, Marsden (2001) reports that business and professional contacts are a frequent source of recruitment in more than one fifth of surveyed establishments. Employers are more likely to rely on this type of interpersonal ties when recruiting for managerial, professionals/technical or sales/services positions than for semi-skilled or unskilled ones. This same finding is supported by an empirical study of Dutch organizations (Gërxhani and Koster forthcoming). Petersen et al. (2000), analyzing the personnel record of a high-tech firm in the United States, find that professional networks are one of the two main entry routes into the organization, used by 9.4 percent of applicants and 13.2 percent of those receiving a job offer. A Swedish study shows that references from former employers and personal contacts are among the most important sources of information for employers when choosing the person to be hired (Behrenz 2001). Pinkston (2012), using an employer survey conducted for the U.S. Department of Labor, reports that referrals from other employers provide respondents with more information than other recruitment channels. Once hired, referred employees tend to earn higher wages and to be more productive than non-referred ones. Moreover, the same study shows that the effects of referrals on the flow of information are substantial: on average, it takes employers almost one and a half years to learn as much about a non-referred employee as they know about an employee referred by an employer from another firm.

Though important, these studies do not go in depth in examining why and when employers use their own business and professional contacts in deciding whom to hire. ${ }^{3}$ Studies focusing on referrals from incumbent employees, on the other hand, look more closely at the mechanisms underlying employers' benefits from recruiting informally. ${ }^{4}$ In particular, Fernandez et al. (2000) distinguish between five distinct mechanisms. Thanks to network contacts of their incumbent employees, employers can tap into a pool of applicants that would not be reached otherwise (mechanism 1: applicant pool expansion). As the contacts making the referral are concerned about their reputation within the organization, they will tend to refer only qualified applicants (mechanism 2: reputation protection). Referrers, having survived previous screening processes, are a positively selected group and by putting in a good word for individuals who are alike will generate a qualified pool of applicants (mechanism 3: homophily). In addition, referrers can pass on information that is difficult to measure or not readily observable by the employer (e.g. about applicants' soft skills, attitudes, work ethic) and at the same time provide applicants with inside knowledge about the job and the workplace (mechanism 4: informational advantages). Referrals from incumbent employees can yield post-hire advantages, as established relationships between

\footnotetext{
${ }^{3}$ Mencken and Winfield (1998) argue that employers consider 'quality of applicants' as the main advantage of informal recruitment via business or professional contacts, especially in small and private sector organisations. However, the reason why business and professional contacts of the employer refer applicants of such quality is left undiscussed.

${ }^{4}$ Referrals from incumbent employees have also been studied in the personnel selection literature. Two mechanisms are usually discussed as to why referrals are associated with better pre- and post-hire outcomes: the realism hypothesis and the individual difference hypothesis (see Breaugh 2012 for more details). Also in this literature, however, the proposed mechanisms are not related to other types of referrals, e.g. referrals from business and professional contacts of the employer.
} 
referrers and referred on the one hand, and better knowledge of both the job content and of the job setting on the other hand, can ease the transition into a new workplace (mechanism 5: social enrichment). In more recent work, Fernandez and Galperin (2014) discuss an additional mechanism that may explain employers' use of referrals, namely the fact that the refereed are due an extra look out of courtesy to the referring contact (mechanism 6: courtesy).

These same mechanisms can also underlie employers' decision to hire referrals from their business and professional contacts. Though it is not our goal to test these mechanisms, we discuss them here in order to provide theoretical explanations as to why and how employers' professional networks would possibly matter. Four of these mechanisms are relevant to our theoretical analysis. ${ }^{5}$ Employers expect business and professional contacts to refer qualified applicants who are suitable for the job and may thus be more easily trainable, as the contacts making the referrals are concerned about their reputation in a shared business environment and will in turn be reciprocated (reputation protection) (Gërxhani et al. 2013). An applicant referred to an employer by the latter's business and professional contacts will likely be more similar to both the contact making the referral and to the employer than non-referred applicants. This similarity may be rewarded as it may indicate a better compatibility with the new organization (homophily) (Fairchild and Robinson 2004, Fernandez and Galperin 2014). Applicants that have been referred by business and professional contacts of the employer may also signal a "capacity to invest in and draw on interpersonal social capital, and thereby to succeed in the position in question” (Marsden 2001: 108). Erickson (2001) makes a similar argument: job applicants with access to a large and varied network of contacts can signal to employers the possibility to exploit these resources, once hired. These contacts may be helpful even in the post-hire phase, as they can provide mentoring or information on tacit aspects of the job, and aid newcomers in the organizational socialization process, just as in the case of referrals from incumbents. Therefore, by choosing to hire applicants recruited via this type of referrals, employers may anticipate the attainment of positive post-hire outcomes (e.g. social enrichment). Finally, employers may consider hiring a referred applicant simply out of courtesy to the employers' business and professional contact making the referral (courtesy).

This discussion leads to the following hypotheses:

\footnotetext{
${ }^{5}$ The mechanisms of applicant pool expansion and informational advantages will not be discussed further for the following reasons. Empirically, we use a factorial survey in which, by design, applicant pools are predetermined. In other words, our focus lies in the advantages that employers derive from their interpersonal ties when the applicant pool to be hired from is held constant. The mechanism of informational advantages cannot be at work because in our design employers do not receive any additional information from the contact: they are simply told that the applicants have been referred by the contact. In addition, such a mechanism works under the assumption that the information given by a business and professional contact is positive. This information can however be negative as well (see Neckerman and Fernandez 2003 for a discussion of this issue in relation to referrals from incumbent employees). We are thankful to Roberto Fernandez for pointing this out to us in a personal note.
} 
Hypothesis 1a: Applicants referred by business and professional contacts of a prospective employer are more likely to be hired than non-referred applicants.

Hypothesis 1b: Applicants referred by business and professional contacts of a prospective employer are more easily trainable than non-referred applicants.

Hypothesis 1c: Applicants referred by business and professional contacts of a prospective employer fit better in their new working environment than non-referred applicants.

While we cannot adjudicate between the mechanisms underlying these hypotheses, we can show whether referrals matter in the hiring process even when two possible mechanisms identified in earlier studies are ruled out by design (applicant pool expansion, informational advantages). Positive effects of referrals on the three hiring-related outcomes would suggest that referrals matter also when employers' business and professional contacts do not provide them with an expanded pool of applicants, or with any additional information on the applicants. A lack of evidence for a referral effect could either mean that business referrals do not matter in the context under study, or that the mechanisms at work are not the ones we are able to capture with our design.

\subsection{Informal recruitment and the screening of educational qualifications}

Signaling theory (Spence 1974) argues that employers, when hiring, have very little information about the productivity and commitment of prospective employees. In order to make their hiring decisions, employers rely on signals from the education system (e.g. type of qualifications, grades, coursework, or duration of studies). However, some authors (Rosenbaum et al. 1990, Miller and Rosenbaum 1997, Brinton and Kariya 1998) have nuanced this theory with the observation that signals are trusted by employers only if embedded in a context of on-going social or institutional relationships. On the basis of interviews with 51 employers in Chicago and its western suburbs, Miller and Rosenbaum (1997: 499) argue that "social infrastructure not only is the means by which information is conveyed but also influences the ways in which employers view information and particularly whether they trust it”. Despite employers' stated needs for academic skills, and the fact that schools could provide information about school leavers' academic performance (e.g. grades, school transcripts, or teacher recommendations), employers in this study rarely based their hiring decisions on information received from schools and explicitly mentioned that they did not consider it trustworthy. To cope with the problem of mistrust, employers depended on information that is "conveyed within a social context of an on-going relationship" (p. 500) and relied on recruiting networks. These networks can be more or less institutionalized. In some countries, like Germany and Japan, institutional linkages between schools and employers are well-developed and information received from schools is perceived as reliable and highly regarded. Elsewhere, like in the United States or in the United Kingdom, long- 
term ties between teachers and employers may improve the role of grades or school transcripts as signals (Rosenbaum et al. 1990).

As argued above (c.f. 2.1), interpersonal ties can provide advantages that may improve signaling during the hiring process. This is particularly relevant since a hiring process involves first a recruitment phase in which various recruitment channels are used to attract applicants, and then a screening phase where a hiring decision is made based on a ranking of various criteria like education, work experience, etc. (Barron and Bishop 1986). When these criteria are perceived as insufficient, unclear or unreliable, social contacts used through informal recruitment may play a crucial role, ensuring that employers can rely on the information available during the screening phase.

In a relatively more recent study, Jackson et al. (2005) discuss the role of educational qualifications as screening criteria from the employers' perspective. The main functions that employers associate with education involve 'certifying' acquired knowledge and 'signaling' less readily or non-observable characteristics of an applicant like motivation, trainability, compatibility with the organization, etc. Based on content analysis of job newspaper advertisements in England, their study shows that both functions are decreasing in value in the eyes of employers. Important for our study, they also observe that "if qualifications do thus decline in value as a signal, an incentive is created for employers to look for alternative, or at all events supplementary signals” (p. 12). We argue here that one way through which employers can compensate for poor or decreasing education signaling is by turning to their own business and professional contacts. This expectation is consistent with the argument of Fernandez et al. (2000: 1338) that "if the characteristics being screened for are easy to measure, then there is no independent benefit to the company in preferring referrals once recruiters apply their screen”. On the other hand, if the characteristics being screened for are noisy signals, then employers are more likely to get some additional benefit from preferring referrals. This argument holds under the condition that the information passed on through social contacts is trustworthy, which can be expected as the contacts making the referrals want to protect their reputation. In other words, referrals provide employers with the additional guarantee that the noisy signals of educational qualifications can be trusted. Hence:

Hypothesis 2a: The effect of referrals on applicants' likelihood to be hired is larger for employers who perceive education to be a noisy signal.

Hypothesis 2b: The effect of referrals on the likelihood that the applicants are considered easy to train is larger for employers who perceive education to be a noisy signal.

Hypothesis 2c: The effect of referrals on the likelihood that applicants are considered a good fit with the corporate environment is larger for employers who perceive education to be a noisy signal. 
Finally, the effect of referrals could also vary depending on whether an applicant's level of educational qualification is high or low. Since higher levels of education imply higher levels of formal qualifications an applicant has acquired, employers may be more inclined to rely on their contacts to check upon such qualifications, than in the case of applicants with lower levels of education. Hiring highly educated individuals involves more uncertainty and risk, as higher levels of formal qualifications are typically rewarded more, both intrinsically (e.g. autonomy, participation in decision-making) and extrinsically (e.g. pay-for-performance schemes, career opportunities) by employers (Gallie et al. 2012). In addition, highly educated individuals are the ones that once being hired will typically receive training opportunities and follow career tracks (Flap and Boxman 2001). Given these expected investments, employers would prefer to have some sort of insurance or guarantee that the highly educated applicants will remain in the organization. The employers' interpersonal ties with their business and professional contacts could be seen as such. This yields the following hypothesis:

Hypothesis 3: The effect of referrals on an applicant's likelihood to be hired increases with higher levels of education. ${ }^{6}$

\section{Design, data and method}

\subsection{Counterfactual hiring decisions}

An important contribution of our study is its effort to isolate the role of referrals on employers' hiring decisions. In a critical review of the literature on the role of social ties in the labor market, Mouw (2003) warns researchers against the risk of confounding the effect of social capital with spurious correlations due to the non-random acquisition of friendship ties. He proposes a test to assess the causal effect of networks (i.e. the information that social ties can provide and that job-seekers are able to access in order to find a job) on labor market outcomes. If contacts really matter, "then well-connected individuals should be more likely to obtain their job through contacts than otherwise identical individuals who are not wellconnected” (Mouw 2003: 873). A comparison between networked job-seekers and otherwise identical individuals who cannot access their contacts (e.g. who during their search cannot obtain information about available jobs from friends, relatives or other acquaintances) implies a counterfactual comparison.

In a similar vein, but from the perspective of employers, Fernandez and Galperin (2014) emphasize the importance of discussing counterfactual hiring decisions of firms that recruit via networks. They observe that "simply put, for the causal effect to be identified, the analysis needs to address what the hiring outcome would have been if not for the firm's use of the network in recruiting” (p. 449). In studies based on personnel records, employers'

\footnotetext{
${ }^{6}$ Note that we only focus on the hiring propensity, as this is the only variable that has direct implication on turnover and replacement costs.
} 
higher likelihood to hire referrals could partly be confounded with the role of other factors that remain unobservable to the researcher, but are known to the employer when making the hiring decision. To the extent that these factors are correlated with both the likelihood of the applicants to be part of a network and with applicants' likelihood to be hired, then the network effect would be spurious.

For our research interests, the core issue is determining what employers' assessments would be if job applicants were not referred by a business and professional contact. Previous studies have applied laboratory experiments (with students) to control for the type of information about prospective employees that is available to the employer (Schram et al. 2010, Gërxhani et al. 2013). Alternatively, Pinkston (2012) compared pairs of individuals employed in the same firm for the same job but differing in their referral status, thus differencing out job- and firm-specific characteristics. In our study, we follow the suggestion of Fernandez and Galperin (2012) and compare employers' assessments of job applicants that are not referred, to the assessments that the same applicants would receive if they were referred by employers' professional and business contacts. In order to do so, we rely on a factorial survey carried out with a sample of human resource professionals. Compared to other studies, the main advantage of our method is the possibility to compare assessments made by the same employer for the same type of job, before and after the recruitment source is disclosed (on the contrary, personnel records usually pool together data on employees that have been assessed by different recruiters at several points in time, and for jobs that are often not comparable). Using this method, we test whether applicants receive better assessments if referred by business and professional contacts of the employer, with a particular focus on: (i) the role of referrals for employers who do not consider education a signal of applicants' trainability and corporate fit; and (ii) the role of referrals for applicants with different levels of educational qualifications.

\subsection{Data and method}

\section{Respondents}

Our study is based on a simulation of a hiring process with a sample of employers (represented by human resource professionals) in the Information, Communication and Technology (henceforth: ICT) sector in England. The data collection took place between May and November 2012, as part of a broader project on job matching and the role of qualifications in the hiring process. ${ }^{7}$ Respondents were employed in companies affiliated with either of the two ICT trade associations operating in England (UKITA, the trade association for ICT small and medium-sized enterprises, and INTELLECT, the trade association for the technology industry), and randomly sampled from the associations' membership records. They were contacted by phone or email and invited to take part in an online survey.

\footnotetext{
7 The ICT sector was of substantial interest for the broader project (see Di Stasio 2013 for a more detailed discussion). We address the issue of the generalizability of our findings in the conclusions.
} 
In total, 172 organizations were targeted, and 34 human resource professionals participated in the survey, yielding a 20 percent response rate, consistent with other studies targeting employers (e.g. Huselid 1995; for a meta-analysis see Baruch and Holtom 2008). All respondents evaluated a set of vignettes describing hypothetical profiles of job applicants, using a web-based factorial survey. 22 of these professionals were also asked to rate an additional set of vignettes, where information on the informal recruitment channel was provided (as explained in detail below). The socio-demographic characteristics of these respondents and of their organizations are summarized in Table 1. Nearly all respondents are highly educated, and there is a balanced representation across genders. Their age ranged between 25 and over 55. The majority of respondents have at least three years of experience in personnel selection, confirming that we targeted decision-makers with some established expertise in making hiring decisions. Our sample included both private and public sector organizations, and guaranteed that both large organizations and organizations of small or medium size were covered. In Table 1, we also compare the size of organizations in our sample with the size of all targeted organizations, thus taking non-respondents into account. As shown in the table, large organizations are well-represented in our sample whereas small organizations (with less than 50 employees) were somewhat more likely to participate in the study than medium-sized organizations (with more than 50 employees). ${ }^{8}$ Finally, almost 80 percent of our respondents regularly solicit referrals from business and professional contacts while recruiting, suggesting that this type of referrals is a frequent source of bringing in new recruits. This assures us that the employers' task to rate referred versus non- referred applicants in the simulation is close to real organizational practices.

\section{TABLE 1 HERE}

\section{Factorial survey}

We simulated a hiring process using a web-based factorial survey (Rossi and Anderson 1982, Jasso 2006, Wallander 2009), a technique widely applied in research on deviant behavior and on justice evaluations, but less known in labor market sociology. Employers rated a series of vignettes showing hypothetical descriptions of job applicants, which had been created through a random combination of a few characteristics of interest. These characteristics were: gender of the applicant, previous work experience, participation in an internship at the

\footnotetext{
${ }^{8}$ When sampling organizations, we tried to ensure an adequate coverage of small, medium-sized and large organizations. However, in some cases, the number of employees reported by the respondent did not correspond to the number of employees mentioned in the membership records from which the organizations were sampled. This may explain the slight under-representation of medium-sized organizations in our sample. The representativeness of our sample can also be assessed based on a comparison with Eurostat data on business demographics in computer programming, consultancy and related activities (NACE code 62) in the United Kingdom (data refer to the year 2010 and were not available for England alone). When considering organizations with more than 10 employees, 30 percent of employees are found in small organizations, 26 percent in medium-sized organizations, and 44 percent in large organizations, largely comparable with the distributions of organizations in our sample.
} 
employer's firm, level of education, field of study, study duration, grade point average, extracurricular activities (see Appendix A). We measured employers' ratings on a scale from 0 to 100 , in terms of agreement with the following three statements: i) it is likely that I will hire the applicant; ii) it is likely that the applicant, if hired, will be easy to train; iii) it is likely that the applicant, if hired, would fit well with the corporate culture of my organization. Thus, our first dependent variable measures employers' hiring propensity, whereas the second and third ones capture the trainability and fit with the organization, respectively. These latter aspects are commonly discussed among the expected benefits of recruiting informally (Fernandez et al. 2000, Marsden and Gorman 2001). At the end of the hiring simulation, employers filled out a questionnaire about their recruitment and selection practices, and the characteristics of their organization. Among the aspects addressed in the questionnaire, employers were asked to specify the recruitment channels regularly activated by their organization when reaching out to potential job applicants. A few questions dealt with the role of education as a signal. For example, employers were asked to indicate whether or not they considered education a signal of trainability, or of fit with the corporate environment.

The hiring simulation was divided into two parts. In the first part (time1), we asked employers to rate 18 hypothetical profiles of job applicants, shown in random order (first rating task). We then told them to give a closer look at a shortlist of the five best-rated profiles and to rank them in order of preference in view of a job interview (first ranking task). In a further step, additional information about applicants' communication and networking skills was added to the same vignettes to simulate a job interview. Employers re-ranked these profiles (second ranking task). After all these steps, employers were told that the five shortlisted applicants were no longer available and the experimental manipulation started (time2). In this second part of the simulation, respondents were shown five additional applicants who had been referred by one of their business and professional contacts and rated them on our three dependent variables of interest (second rating task). Unbeknownst to employers, these additional profiles were identical to five of the profiles already rated in the first part of the simulation, except for their referral status. The instructions given to respondents are reported in appendix B. ${ }^{9}$ Thus, the only difference between the first and the second sets of ratings is that, for the latter, the recruitment source was known. Given that for the first set the recruitment source was not yet revealed, these ratings can be treated as baseline counterfactuals of what the hiring decision would have been in the absence of referral.

\footnotetext{
${ }^{9}$ Note that between the time employers rated the five 'non-referred' profiles in the first part and the time they rated the same 'referred' profiles in the second part, employers had various other evaluation steps. Moreover, additional information on applicants' skills were provided as a filler. For this reason, we believe it is very unlikely that employers were able to precisely recall what the vignettes introduced in random order during the rating tasks looked like. We can however not exclude the possibility that they understood the experimental manipulation. In that case, we would expect them to rate referrals and non-referrals similarly, implying an underestimated referral effect. We are grateful to an anonymous reviewer for this latter observation. It is likely that employers who did not understand the manipulation may still be wary of revealing their preferences for referrals due to social desirability bias (as network-based hiring may be considered a sort of preferential treatment). Even in this case, our estimates for the referral effect would be conservative.
} 
For the empirical analysis, we focus only on the subset of vignettes, five per employer, that received multiple ratings. Our design can be considered a particular application of a multiple segment factorial vignette design (Ganong and Coleman 2006), in which the description contained in a vignette develops over multiple segments. The only difference in our design is that respondents were told that they were dealing with different applicants at time2, and the new information added to the vignettes (referral status) was held constant across employers. Therefore, referral status is, by design, uncorrelated with the vignette characteristics. Our main focus is on the sign and significance of the coefficient for referral status, and on whether this effect varies depending on: (i) the signaling role of education; and (ii) an applicant's level of education. The characteristics of (referred) applicants, and descriptive statistics of the ratings, are reported in Table 2.

\section{TABLE 2 HERE}

\section{Estimation method}

To test our hypotheses 1a-1c, we compare employers' ratings before the recruitment method was revealed, with the ratings given after knowing that one of their business or professional contacts had made a referral. As ratings have been collected before and after the referral source was disclosed, a paired t-test would give us an unbiased measure of the difference in ratings that is due to referrals, averaged across respondents. However, the fact that multiple vignettes were rated by the same employer would bias the standard errors downwards, if the nesting structure of the data were not properly accounted for. Thus, we reshaped our dataset into a long format. Referral status is captured by a dummy variable taking the value of 0 at time1 and value of 1 at time2, after information about informal recruitment is disclosed. We regressed ratings on referral status, using fixed effects for employers to obtain correct standard errors. As the dependent variables were right-skewed, we took their square root to obtain more reliable estimates. We focus on the coefficient for referral status, which represents the change in ratings that occurs after the recruitment source has been revealed.

With this model, we also implicitly control for any characteristic of the employers or their organizations that may affect the ratings. The model relies exclusively on within-employer variability of the ratings and of covariates in the estimation of the regression coefficients. Our dependent variables measure employers' ratings of the likelihood that: (1) they would hire the job applicant; (2) the applicant, if hired, would be easily trainable; and (3) the applicant, if hired, would fit well in the new working environment. Thus, for each of the three dependent variables, we fit three models. The first model (M1) tests hypotheses 1a-1c by reporting the effect of applicants' referral status, without any additional control as referral status was an exogenous variable in our design. The second model (M2) tests hypotheses 2a-2c by adding the interaction term between referral status and employers' views about the signaling role of education. The latter is captured by two dummy variables, which were coded 1 if the employer mentioned in the survey that education is a signal of, respectively, trainability or fit 
with the corporate environment (i.e. good signal), and 0 otherwise (i.e. poor signal). Finally, the third model (M3) tests hypothesis 3 by adding an interaction term between referral status and an applicant's level of education.

\section{Results and discussion}

Table 3 shows the results of several linear regression models, with fixed effects for employers. Results are presented in separate panels for each of the three dependent variables. As reported in the first model (M1) in all three panels, once employers know that applicants have been referred, they tend to give more positive ratings: the average difference in ratings that is due to referrals is positive for all three dependent variables. Knowing that the applicants have been referred by a business and professional contact improves employers' hiring propensity and expectations regarding future trainability and corporate fit. As referral status was by design uncorrelated with the vignette characteristics, the higher ratings obtained by referred applicants cannot be due to unobserved differences in applicants' likelihood to be part of an employer's network. By ruling out this possibility, we can be sure that the effect of referrals is not spurious, as discussed in Fernandez and Galperin (2014) for employers and in Mouw (2003) for employees. However, though differences in ratings are in the expected direction for all three measurements, they are only statistically significant at $\mathrm{p}<0.1$ (95\% C.I. $-0.029,0.554)$ for the measure of trainability, and the effect size is rather small. These findings provide only modest support for hypothesis $1 \mathrm{~b}$, but no support for hypotheses $1 \mathrm{a}$ and 1c.

It is important to emphasize that our design ruled out some of the mechanisms through which referrals may exert their effect in the labor market. To the extent that referrals matter for their role in expanding the pool of applicants or of bringing tangible informational advantages to employers, we were not able to capture these processes with our hiring simulation. We also believe that the difference in ratings due to the referral status may be an underestimation of the true effect of referrals for two reasons. First, in our study employers were simply informed that the applicant had been referred by one of their business and professional contacts, without specifying which kind of relationship existed between the applicant and the common contact (e.g. whether the contact was a former employer of the applicant, or had screened the applicant before). The effect of referrals might have been higher if employers knew that the contact making the referral had the opportunity in the past to observe the performance of the applicant, as demonstrated by Antoninis (2006) and Gërxhani et al. (2013) for the relationship between referrals and wages. The second reason has to do with our factorial survey design. Since referrals were hypothetical, it is likely that they weigh less in affecting employers' ratings than if referrals were 'real' and thus more accountable. ${ }^{10}$ Therefore, we consider our results as conservative estimates of the effect of referrals on the three dependent variables.

\footnotetext{
${ }^{10}$ We are grateful to an anonymous referee for emphasizing this argument.
} 


\section{TABLE 3 HERE}

We now turn to examine the effect of referrals in relation to the signaling role of educational qualifications. In the second models (M2) of Table 3, we tested whether the referral effect is larger for those employers who consider education a poor signal by introducing an interaction effect between referral status and the variables measuring employers' views about the role of education as a signal of, respectively, trainability and fit with the corporate environment. The coefficient for referral status in M2T (Panel 1) represents the effect of referrals for those employers who consider education a poor signal of trainability and is statistically significant (0.444 at $\mathrm{p}<0.05$; C.I. 0.007, 0.882). Similarly, the effect of referrals on the trainability ratings (M2 in Panel 2) is larger and significant for employers who do not consider education a signal of trainability $(0.516$, at $\mathrm{p}<0.01 ; 95 \%$ C.I. $0.140,0.892)$. The estimates for the interaction terms suggest that only when applicants' trainability cannot be discerned from educational qualifications employers tend to rely on referrals from their business and professional contacts. Finally, the interaction effect for the ratings of corporate fit (M2 in Panel 3), though in the expected direction, does not reach conventional levels of significance. Model M2F in Panel 1 also suggests that the effect of referrals on hiring propensity does not vary depending on whether employers consider education a signal of fit with the corporate environment. ${ }^{11}$ These findings support hypotheses $2 \mathrm{a}$ (partly) and 2b, but not hypothesis 2c.

To test hypothesis 3, we interacted referral status with applicants' level of education. The third model (M3 in Panel 1) of Table 3 shows that when applicants are referred, there is a stronger differentiation in ratings across educational levels, suggesting that the role of employers' business and professional contacts varies depending on an applicant's level of education. In particular, the effect of referrals is larger for higher levels of education. Hypothesis 3 is thus supported.

It is worth noting that the referral effect is the strongest for applicants that have followed a university master's program, whereas for applicants with non-tertiary education (A-level) the effect of referrals is even negative. Ratings for applicants with non-tertiary education decrease after the informal recruitment source is disclosed, though the effect is not statistically significant. It appears that the presence of referrals starts to pay off at a certain level of formal qualifications. We interpret our findings based on the mechanism of homophily described earlier in the paper. ${ }^{12}$ Since most employers in our sample have a tertiary degree (c.f. Table 2), according to the homophily argument they would expect referred applicants to have an educational level similar to them and their contacts. If the

\footnotetext{
${ }^{11}$ We can speculate that fit is less important in jobs of a rather technical nature such as the ones under study here; indeed, a very low number of employers mentioned that they consider education a signal of fit with the corporate culture when hiring for ICT jobs.

${ }^{12}$ Again, we do not test whether this mechanism is at play, as it is beyond the goal of our study. We simply draw on our theoretical discussion to better understand our empirical results.
} 
educational level is lower, but applicants are still referred, it may make employers suspicious on whether they can rely on the referrals. As a result, employers 'punish' non-tertiary applicants by giving them more negative ratings if referred.

Employers seem to 'reward' the master-level applicants the most. Given that the entry requirement for the type of jobs we study here is a bachelor degree (as reported by employers themselves in the accompanying questionnaire), a priori it seems unnecessary to value a master degree more than a bachelor degree, as master-level applicants would be overeducated for the job at hand. To hire "atypically highly credentialed candidates", employers need some insurance against the risk that the overeducated applicants may leave the organization (Bills 1992). When master-level applicants are referred, employers' interpersonal ties seem to provide this guarantee.

Before concluding, two caveats related to order and carryover effects need to be addressed. Order effects may occur to the extent that employers' responses were affected by the sequencing of the information. In our design, in order to elicit employers' ratings after the recruitment source was disclosed, we told employers that the job applicants they had shortlisted had found other jobs in the meantime. ${ }^{13}$ This setup may have given employers the impression that they were operating in a tight labor market, which could trigger different responses to the use of particular types of recruitment channels (e.g. Henkens et al. 2005). In our analysis, we could not test whether employers' decisions were influenced by perceptions of labor market tightness. However, to provide a robustness check for our results, we analyzed ratings collected from a control group of 12 additional employers (the remaining respondents from the 34 who initially accepted to take part in the study). The first stage of the vignette study was identical to the one previously discussed. After a shortlist of applicants was created, employers in the control group were told that the shortlisted ones withdrew their applications as they had found another job in the meantime. As an alternative, employers could re-screen the remaining five best-rated applicants from the initial pool. Importantly, these re-screened applicants were not recruited via referrals. Table 4 reports a comparison of ratings at time 1 and time 2 for employers in the control group. If labor market tightness would play a role, one would expect employers' second ratings to be higher: in the absence of additional applicants to screen, employers are likely to reconsider the rated applicants as the available pool in the labor market is limited. This was not the case: for all three dependent variables, ratings at time 2 were significantly lower. The fact that employers' behavior was the opposite in the presence of referrals (cf. models M1 of Table 3) excludes the possibility that the reported difference in ratings that we attributed to referrals is, instead, related to perceived labor market tightness.

\footnotetext{
${ }^{13}$ This strategy was necessary in order to gather employers' ratings about referred applicants. Admittedly, a better alternative would be to mention the recruitment channel among the characteristics that are listed in the vignettes. However, our study is part of a broader survey that was originally designed for other purposes and it was not possible to include the recruitment channel in the description of the profiles.
} 


\section{TABLE 4 HERE}

Carryover effects are also likely as in our study we assumed stability of ratings across vignettes that were rated by the same employer. In other words, we assumed that employers would give the same rating as long as the characteristics of the applicant remained identical, regardless of the applicants that had already been rated during the rest of the simulation. Following Hainmueller et al. (2013), we tested the plausibility of this assumption using only the first vignette that was shown to respondents after the experimental manipulation. Our pattern of results is confirmed.

\section{Conclusions}

This study makes a threefold contribution to sociological research on the importance of ties in the labor market. First, our focus on employers and in particular on their business and professional contacts adds to a body of literature that has either primarily concentrated on supply-side explanations or, when considering the demand-side, it has mainly focused on the social contacts of incumbent employees. Second, by combining the factorial survey with an experimental manipulation we created counterfactual hiring decisions in order to compare how identical job applicants are perceived in the presence or absence of referrals from employers' business and professional contacts. In so doing, we provide a test of the effect of social contacts on employers' hiring assessments that copes with the issue of endogeneity. Third, we argue theoretically and show empirically that for a better understanding of the hiring process, the screening of applicants' characteristics and the method through which applicants are recruited should be considered jointly, as this is how employers assess applications in real labor markets.

By developing baseline counterfactuals for how applicants would be rated if not referred, we were able to capture the change in ratings that was due to a referral from one of employers' business or professional contacts. By design, employers in our study were only informed about the presence (or not) of referrals and were not given any additional information about referred applicants (i.e. the mechanism of information advantages). Our findings suggest that simply knowing that an applicant has been referred is not sufficient; the informational advantages yielded from being referred seem to be necessary for employers to consider the benefit of recruiting informally. As shown elsewhere (e.g. Fernandez et al. 2000), employers value referrals for the additional information they bring about applicants' hard-to-measure characteristics, such as work attitude, trainability, commitment. These characteristics were not included in our vignette design: thus, employers may have seen little benefit from preferring referrals over non-referrals, as the two were identical on all other observable characteristics. Nevertheless, if the characteristics being screened for are noisy signals (i.e. if education is not considered a signal of trainability), then our study shows that referred 
applicants are more likely to be hired and are seen as more trainable than otherwise identical applicants who are not referred. This reinforces the argument made in the literature that, when formal educational qualifications are perceived as noisy signals, informal recruitment channels can represent a compensatory strategy for employers to deal with poor signaling (Marsden 2001).

More generally, the referral effect is more noticeable at higher educational levels, as the fact of being referred when holding a master-degree may be seen by employers as some form of guarantee that these overeducated applicants will not leave their organization for jobs that better match their level of education. On the other hand, non-tertiary applicants are even 'punished' when referred, by being rated negatively by the employers. This has likely to do with employers' suspicion and distrust arising when realizing that applicants of lower levels of education than expected were referred to them.

Other authors have proposed that for jobs with very technical requirements, such as the ones under study in this paper, informal recruitment channels may be superfluous, as formal credentials already provide specific information about applicants' knowledge and skills (Lin 1999). However, according to our study, this observation should be further qualified. When formal education does not provide, in and of itself, clear signals to employers, interpersonal ties are relied upon to provide more credible information than what is conveyed through poorly understood qualifications. In this study, we have found preliminary evidence for the claim that social contacts can correct for poor signaling: as previously noted by Miller and Rosenbaum (1997: 517), "employers must not only receive information but receive it in the context of a social infrastructure that reassures them of its trustworthiness and relevance”.

Our study does not come without limitations. We are aware of the small size of our sample, which may explain the non-significance of some of the regression coefficients, and admittedly limits the generalizability of our findings. In future research, we plan to test the referral effect with a larger sample, using population-based survey experiments (Mutz 2011). Also, data were gathered as part of a larger project, and various choices were constrained by the setup of a hiring simulation originally designed for other purposes. We are reassured by the fact that order effects, priming, or social desirability bias, if present, would indicate that our estimates of referral effects are on the conservative side. Future studies could be designed from the start with the aim to isolate the various mechanisms. For instance, the possibility to vary the quantity and quality of information about referred applicants would allow for a proper test of the mechanism of informational advantages, which we had to rule out by design. Similarly, future research could explore whether referral effects vary depending on the contact making the referral and the strength of her relationship with the employer.

Our study has important policy implications. Researchers and policy-makers alike regularly voice concerns about the failure of the British education system to prepare students for specific occupations, especially if compared to countries like Germany or the Netherlands, where vocational schools are better attuned to labor market needs. Our findings support the idea that in contexts with noisy signals, school leavers entering their first job may benefit 
from interpersonal ties with business and professional contacts of their prospective employers. However, employers' decisions to recruit informally are not randomly distributed, nor are referrals from business and professional contacts. Future studies should consider more closely the motives that underlie employers' preferences for informal recruitment channels, and the factors associated with such choice (e.g. Mencken and Winfield 1998, Gërxhani et al. 2013, Gërxhani and Koster forthcoming). Given the social inequalities that may arise due to unequal access to networks, it would be better if these ties were to be transformed into institutionalized pathways of interaction between schools and employers (Brinton and Kariya 1998, Rosenbaum et al. 1990). Increasing collaborations between schools and employers may significantly contribute to youth's employment opportunities: for instance, by taking part in sandwich degree placements students build a network of professional contacts and potential referrers that may prove useful in gaining access to jobs (Purcell et al. 2002).

Finally, our study focused on England, a country in which the education system does not give employers specific information about job applicants. One could argue that in England the less strict legislation on dismissals allows employers to correct for bad matches at a relatively low cost (Breen 2005) and should reduce their concerns at the hiring stage even in the absence of referrals (thus reducing the difference in ratings). We do not know, however, whether the same considerations would be applicable in countries characterized by different institutional arrangements (e.g. Germany or the Netherlands, where educational signaling is high). This also opens up opportunities for future research. 


\section{Acknowledgements}

This research is supported by the Dutch Organization for Scientific Research (NWO), grant \#452-07-002. Findings discussed in this article have been presented at the conference organized by the European Consortium for Sociological Research in September 2012 at Stockholm University (Stockholm, Sweden). The authors are grateful to Adam Booij, Thijs Bol, Roberto Fernandez, Daniela Grunow, Herman van de Werfhorst, Olav Velthuis and three anonymous reviewers for their detailed comments on an earlier draft of the article. 


\section{References}

Antoninis, M., 2006. The wage effects from the use of personal contacts as hiring channels. Journal of Economic Behavior and Organization, 59, 133-146.

Barron, J.M., Bishop, J., 1985. Extensive Search, Intensive Search, and Hiring Costs: New Evidence on Employer Hiring Activity. Economic Inquiry, 23, 363-383.

Baruch, Y., Holtom, B. C. 2008. Survey response rate levels and trends in organizational research. Human Relations, 61, 1139-1160.

Behrenz, L., 2001. Who gets the job and why? An explorative study of employers' recruitment behavior. Journal of Applied Economics, 4, 255-278.

Bills, D.B. (1992). The Mutability of Educational Credentials as Hiring Criteria. How Employers Evaluate Atypically Highly Credentialed Job Candidates. Work and Occupations, 19, 79:95.

Boxman, A.W., De Graaf, P.M. and Flap, H.D., 1991. The impact of social and human capital on the income attainment of Dutch managers. Social Networks, 13, 51-73.

Breaugh, J. A., 2012. Employee Recruitment. Annual Review of Psychology, 64, 389-416.

Breen, R., 2005. Explaining Cross-national Variation in Youth Unemployment: Market and Institutional Factors. European Sociological Review, 21, 125-134.

Brinton, M., Kariya, T., 1998. Institutional embeddedness in Japanese labor markets. In: Brinton, M.C. and Nee, V. (Eds.). The New Institutionalism in Sociology. Stanford: Standford University Press, pp. 181-207.

De Graaf, N.D., Flap, H.D., 1988. With a little help from my friends. Social resources as an explanation of occupational status and income in the Netherlands, the United States and West Germany. Social Forces, 67, 453-472.

Di Stasio, V., 2013. Why education matters to employers. A vignette study in Italy, England and the Netherlands. Dissertation manuscript. University of Amsterdam, the Netherlands.

Erickson, B.H., 2001. Good networks and good jobs: the value of social capital to employers and employees. In: Lin, N, Cook, K. and Burt, R. S. (Eds.) Social capital: theory and research. New Brunswick, NJ; London: Aldine Transaction, pp. 127-158.

Fairchild, G.B., Robinson, J.A., 2004. It's What You Know and Who They Know: Weak Ties and Strong Ties in Urban Labor Markets. Academy of Management Proceedings, 1, G1-G4.

Fernandez, R.M., Galperin, R.V., 2014. The Causal Status of Social Capital in Labor Markets. Research in the Sociology of Organizations. 40, 441-457.

Fernandez, R.M., Castilla E., Moore, P., 2000. Social Capital at Work: Networks and Employment at a Phone Center. American Journal of Sociology, 195, 1288-1356. 
Flap, H., Boxman, E., 2001. Getting started: the influence of social capital on the start of the occupational career. In: Lin, N., Cook, K. and Burt, R.S. (Eds.). Social capital: theory and research. New Brunswick, NJ; London: Aldine Transaction, pp. 159-84

Huselid, M.A. 1995. The Impact of Human Resource Management Practices on Turnover, Productivity, and Corporate Financial Performance. The Academy of Management Journal, 38, 635-672.

Gallie D., Felstead A., Green F., 2012. Job preferences and the intrinsic quality of work: the changing attitudes of British employees 1992-2006. Work, employment and society, 26(5), 806-821.

Ganong, L. H., Coleman, M. 2006. Multiple segment factorial vignette designs. Journal of Marriage and the Family, 68, 455-468.

Gërxhani, K., Koster, F. (forthcoming). Making the Right Move: Investigating Employers' Recruitment Strategies. Personnel Review.

Gërxhani, K., Brandts, J., Schram, A. 2013. The Emergence of Employer Information Networks in an Experimental Labor Market. Social Networks, 35, 541-560.

Granovetter, M., 1995. Getting a Job; A Study of Contacts and Careers, $2^{\text {nd }}$ ed. Chicago: University of Chicago Press.

Henkens, K., Remery, C., Schippers, J., 2005. Recruiting personnel in a tight labor market: an analysis of employers’ behavior. International Journal of Manpower, 26, 421-433.

Jackson, M., Goldthorpe J.H., C. Mills 2005. Education, Employers and Class Mobility. Research in Social Stratification and Mobility, 23, 3-33.

Jasso, G., 2006. Factorial Survey Methods for Studying Beliefs and Judgments. Sociological Methods \& Research, 34, 334-423.

Lin, N., 1999. Social networks and status attainment. Annual Review of Sociology, 25, 467487.

Marsden, P.V. 2001. Interpersonal Ties, Social Capital, and Employer Staffing Practices. In: Lin, N., Cook, K. and Burt, R.S. (Eds.) Social Capital: Theory and Research. New Brunswick, NJ; London: Aldine Transaction, pp. 105-125.

Marsden, P.V. and Gorman, E.H. 2001. Social Networks, Job Changes, and Recruitment. In: Berg, I. and Kalleberg, A.L. (Eds.) Sourcebook of Labor Markets: Evolving Structures and Processes. New York: Kluwer Academic/ Plenum Publishers, pp. 467-502.

Mencken, F.C., Winfield I., 1998. In Search of the 'Right Stuff': The Advantages and Disadvantages of Informal and Formal Recruiting Practices in External Labor Markets. American Journal of Economics and Sociology, 57, 135-153. 
Miller, S.R., Rosenbaum, J.E., 1997. 'Hiring in a Hobbesian World: Social Infrastructure and Employers’ Use of Information. Work and Occupations, 24, 498-523.

Montgomery, J.D., 1991. Social Networks and Labor-Market Outcomes: Towards an Economic Analysis. The American Economic Review, 81, 1408-1418.

Mouw, T., 2006. Estimating the Causal Effects of Job Contacts: A Review of Recent Research. Annual Review of Sociology, 32, 79-102.

Mouw, T., 2003. Social Capital and Finding a Job: Do Contacts Matter?. American Sociological Review, 68, 868-898.

Mutz, D.C. 2011. Population-based survey experiments. Princeton University Press.

Neckerman, K.M., Fernandez R.M., 2003. Keeping a Job: Networks Hiring and Turnover in a Retail Bank. Research in the Sociology of Organizations, 20, 299-318.

Petersen, T., Saporta, I., Seidel, M.L., 2000. Offering a Job: Meritocracy and Social Networks. American Journal of Sociology, 106, 763-816.

Pinkston, J C., 2012. How Much Do Employers Learn from Referrals?. Industrial Relations, 51, 317-341.

Purcell, K., Morley, M., Rowley, G., 2002. Employers in the New Graduate Labor Market: recruiting from a wider spectrum of graduates. London: Council for Industry and Higher Education.

Rosenbaum, J.E., Kariya, T., Settersen, R., Maier, T., 1990. Market and Network Theories of the Transition from School to Work: Their Application to Industrialized Societies. Annual Review of Sociology, 16, 263-299.

Rossi, P.H., Nock, S.L., 1982. Measuring Social Judgments: The Factorial Survey Approach. Sage, Beverly Hills.

Scherer, S., 2005. Patterns of Labor Market Entry - Long Wait or Career Instability? An Empirical Comparison of Italy, Great Britain and West Germany. European Sociological Review, 5, 427-440.

Schram, A., Brandts, J., Gërxhani, K., 2010. Information, bilateral negotiations, and worker recruitment. European Economic Review, 54, 1035-1058.

Spence, A.M., 1974. Market Signaling: Information Transfer in Hiring and Related Processes. Harvard University Press, Cambridge.

Wallander, L., 2009. 25 Years of Factorial Surveys in Sociology: A Review. Social Science Research, 38, 505-20. 
Table 1. Characteristics of respondents and their organizations.

\begin{tabular}{|c|c|c|c|c|}
\hline & \multicolumn{4}{|c|}{ Characteristics of employers } \\
\hline & \multicolumn{2}{|c|}{$\%$} & \multicolumn{2}{|c|}{ Freq. } \\
\hline \multicolumn{5}{|l|}{ Gender } \\
\hline Male & \multicolumn{2}{|c|}{54.55} & \multicolumn{2}{|c|}{12} \\
\hline Female & \multicolumn{2}{|c|}{45.45} & \multicolumn{2}{|c|}{10} \\
\hline \multicolumn{5}{|l|}{ Educational background } \\
\hline Non tertiary & \multicolumn{2}{|c|}{5.56} & \multicolumn{2}{|c|}{1} \\
\hline Tertiary, university & \multicolumn{2}{|c|}{88.89} & \multicolumn{2}{|c|}{20} \\
\hline Tertiary, polytechnics & \multicolumn{2}{|c|}{5.56} & \multicolumn{2}{|c|}{1} \\
\hline \multicolumn{5}{|l|}{ Age } \\
\hline $25-34$ & \multicolumn{2}{|c|}{54.57} & \multicolumn{2}{|c|}{12} \\
\hline $35-44$ & \multicolumn{2}{|c|}{27.29} & \multicolumn{2}{|c|}{6} \\
\hline $45-54$ & \multicolumn{2}{|c|}{13.65} & \multicolumn{2}{|c|}{3} \\
\hline 55 or more & \multicolumn{2}{|c|}{4.55} & \multicolumn{2}{|c|}{1} \\
\hline \multicolumn{5}{|l|}{ Experience in personnel selection } \\
\hline$<2$ years & \multicolumn{2}{|c|}{9.09} & \multicolumn{2}{|c|}{2} \\
\hline $3-5$ years & \multicolumn{2}{|c|}{27.27} & \multicolumn{2}{|c|}{6} \\
\hline $6-10$ years & & & & 3 \\
\hline$>10$ years & & & & ; \\
\hline Views about signaling role of education & & & & \\
\hline Education signals trainability & & & & 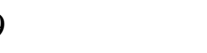 \\
\hline Education signals fit with corporate & & & & \\
\hline & & aracteristic & organizatio & \\
\hline & & & & eq. \\
\hline Sector & & & & \\
\hline Public & & & & \\
\hline Private & & & & \\
\hline Both & & & & 1 \\
\hline Size (n. employees) & $\%$ resp & $\%$ target & Freq. resp & Freq. target \\
\hline Small (from 10 to 49 employees) & 31.82 & 22.67 & 7 & 39 \\
\hline Medium (from 50 to 249 employees) & 13.64 & 23.25 & 3 & 40 \\
\hline Large (more than 250 employees) & 54.55 & 54.07 & 12 & 93 \\
\hline $\begin{array}{l}\text { Regularly recruit via referrals from } \\
\text { business or professional contacts }\end{array}$ & & & & \\
\hline Yes & & & & 7 \\
\hline No & & & & $\dot{q}$ \\
\hline
\end{tabular}

Note: $\mathrm{N}$ total employers $=22$. For the variable 'organization size', we also provide information about organizations that were targeted but did not participate in our survey, to compare the size of the organizations in our sample with the size of the organizations in the target population, which also takes into account nonrespondents. Organization size is the only variable that allows this comparison. 
Table 2. Characteristics of (referred) applicants.

\begin{tabular}{|c|c|c|c|c|}
\hline Vignette characteristics & \multicolumn{2}{|c|}{$\%$} & \multicolumn{2}{|c|}{ Freq. } \\
\hline \multicolumn{5}{|l|}{ Gender } \\
\hline Male & \multicolumn{2}{|c|}{56.36} & \multicolumn{2}{|c|}{62} \\
\hline Female & \multicolumn{2}{|c|}{43.64} & \multicolumn{2}{|c|}{48} \\
\hline \multicolumn{5}{|l|}{ Level of education } \\
\hline Non tertiary & \multicolumn{2}{|c|}{26.36} & \multicolumn{2}{|c|}{29} \\
\hline Tertiary, bachelor & \multicolumn{2}{|c|}{30.91} & \multicolumn{2}{|c|}{34} \\
\hline Tertiary, master & \multicolumn{2}{|c|}{42.73} & \multicolumn{2}{|c|}{47} \\
\hline \multicolumn{5}{|l|}{ Field of study } \\
\hline Informatics & \multicolumn{2}{|c|}{24.55} & \multicolumn{2}{|c|}{27} \\
\hline Economics & \multicolumn{2}{|c|}{35.45} & \multicolumn{2}{|c|}{39} \\
\hline Social Science & \multicolumn{2}{|c|}{40.00} & \multicolumn{2}{|c|}{44} \\
\hline \multicolumn{5}{|l|}{ Study duration } \\
\hline On time & \multicolumn{2}{|c|}{36.36} & \multicolumn{2}{|c|}{40} \\
\hline Two-year delay & \multicolumn{2}{|c|}{35.45} & \multicolumn{2}{|c|}{39} \\
\hline Early drop-out & \multicolumn{2}{|c|}{28.18} & \multicolumn{2}{|c|}{31} \\
\hline \multicolumn{5}{|l|}{ Grade point average } \\
\hline Fair & \multicolumn{2}{|c|}{51.82} & \multicolumn{2}{|c|}{57} \\
\hline Very good & & & & \\
\hline Extra-curricular activities & & & & \\
\hline Yes & & & & \\
\hline No & & & & \\
\hline Previous work experience & & & & \\
\hline Yes & & & & \\
\hline No & & & & \\
\hline Internship at the firm & & & & \\
\hline Yes & & & & \\
\hline No & & & & \\
\hline Ratings (square root) & Mean & $S D$ & Min & Max \\
\hline Likelihood to hire the applicant & 5.099 & 2.270 & 0 & 9.798 \\
\hline Likelihood that the applicant would be easy to train, if hired & 5.485 & 2.333 & 1 & 9.950 \\
\hline $\begin{array}{l}\text { Likelihood that the applicant would fit well with the corporate } \\
\text { culture of the organization }\end{array}$ & 5.658 & 2.254 & 1 & 9.644 \\
\hline
\end{tabular}

Note: $\mathrm{N}$ total applicants $=110 . \mathrm{N}$ total ratings $=220$ (as each applicant was rated twice, when referred and when non-referred). 
Table 3. The role of referrals on employers' ratings: linear regression models with employer fixed effects.

\begin{tabular}{|c|c|c|c|c|c|c|c|c|}
\hline \multirow[b]{3}{*}{ Referral } & \multicolumn{4}{|c|}{$\begin{array}{c}\text { Panel } 1 \\
\text { Likelihood to hire the applicant }\end{array}$} & \multicolumn{2}{|c|}{$\begin{array}{c}\text { Panel } 2 \\
\text { Easy to train, } \\
\text { if hired }\end{array}$} & \multicolumn{2}{|c|}{$\begin{array}{c}\text { Panel } 3 \\
\text { Fit with corporate culture, } \\
\text { if hired } \\
\end{array}$} \\
\hline & M1 & M2T & $M 2 F$ & M3 & M1 & M2 & M1 & M2 \\
\hline & $\begin{array}{c}0.192 \\
(0.171)\end{array}$ & $\begin{array}{l}0.444^{* *} \\
(0.222)\end{array}$ & $\begin{array}{c}0.170 \\
(0.180)\end{array}$ & $\begin{array}{l}-0.536 \\
(0.326)\end{array}$ & $\begin{array}{l}0.262^{*} \\
(0.148)\end{array}$ & $\begin{array}{l}0.516^{* * *} \\
(0.191)\end{array}$ & $\begin{array}{c}0.178 \\
(0.157)\end{array}$ & $\begin{array}{c}0.241 \\
(0.164)\end{array}$ \\
\hline $\begin{array}{l}\text { Level of education (ref. non tertiary) } \\
\text { Bachelor } \\
\text { Master }\end{array}$ & & & & $\begin{array}{c}-0.105 \\
(0.335) \\
0.098 \\
(0.314)\end{array}$ & & & & \\
\hline $\begin{array}{l}\text { Referral* education signaling } \\
\text { Referral*signal of trainability }\end{array}$ & & $\begin{array}{l}-0.616 * \\
(0.347)\end{array}$ & & & & $\begin{array}{l}-0.620^{* *} \\
(0.298)\end{array}$ & & \\
\hline Referral*signal of fit & & & $\begin{array}{c}0.240 \\
(0.598)\end{array}$ & & & & & $\begin{array}{l}-0.689 \\
(0.545)\end{array}$ \\
\hline $\begin{array}{l}\text { Referral*level of education } \\
\text { (ref. non-tertiary) }\end{array}$ & & & & & & & & \\
\hline Referral*Bachelor & & & & $\begin{array}{l}0.884^{* *} \\
(0.443)\end{array}$ & & & & \\
\hline Referral*Master & & & & $\begin{array}{l}1.064^{* *} \\
(0.414)\end{array}$ & & & & \\
\hline Constant & $\begin{array}{l}5.003^{* * *} \\
(0.121)\end{array}$ & $\begin{array}{l}5.003^{* * *} \\
(0.121)\end{array}$ & $\begin{array}{l}5.003^{* * *} \\
(0.121)\end{array}$ & $\begin{array}{l}4.994^{* * *} \\
(0.243)\end{array}$ & $\begin{array}{l}5.354^{* * *} \\
(0.104)\end{array}$ & $\begin{array}{l}5.354^{* * *} \\
(0.104)\end{array}$ & $\begin{array}{l}5.568^{* * *} \\
(0.111)\end{array}$ & $\begin{array}{l}5.568^{* * *} \\
(0.111)\end{array}$ \\
\hline$N$ vignettes & 220 & 220 & 220 & 220 & 220 & 220 & 220 & 220 \\
\hline$N$ employers & 22 & 22 & 22 & 22 & 22 & 22 & 22 & 22 \\
\hline Employer fixed effects & yes & yes & yes & yes & yes & yes & yes & yes \\
\hline
\end{tabular}

Note: Standard errors in parentheses. ${ }^{*} p<0.1,{ }^{* *} p<0.05,{ }^{* * *} p<0.01$.

M1-M3 refer to models 1 to 3; M2T and M2F refer to model 2 when 'referral' is interacted with the measure of trainability signaling and corporate-fit signaling, respectively. 
Table 4. Indirect test of order effects: comparison of ratings for non-referred applicants.

\begin{tabular}{lccc}
\hline & $\begin{array}{c}\text { Likelihood to hire } \\
\text { the applicant }\end{array}$ & $\begin{array}{c}\text { Easy to train, if } \\
\text { hired }\end{array}$ & $\begin{array}{c}\text { Fit with corporate } \\
\text { culture, if hired }\end{array}$ \\
\hline Difference in ratings & $-0.517^{* * *}$ & $-0.483^{* * *}$ & $-0.380^{* * *}$ \\
& $(0.160)$ & $(0.168)$ & $(0.143)$ \\
\hline
\end{tabular}

Note: Standard errors in parentheses. ${ }^{*} p<0.1,{ }^{* *} p<0.05,{ }^{* * *} p<0.01$.

$\mathrm{N}=120$ ratings ( 60 applicants were rated twice, at time1 and at time2, by 12 employers). 


\section{Appendix A.}

Table A1. Factorial survey design.

\begin{tabular}{ll}
\hline Vignette dimensions & \\
\hline 1. Gender & 1. Male \\
& 2. Female \\
2. Previous work experience & 1. Yes \\
& 2. No \\
3. Internship at the firm & 1. Yes \\
& 2. No levels \\
4. Level of education & 1. A-level \\
& 2. University bachelor \\
& 3. University master \\
5. Field of study & 1. Informatics \\
& 2. Economics \\
6. Study duration & 3. Social sciences \\
& 1. Graduated on time \\
7. Grade point average & 2. Graduated with a 2 year-delay \\
& 3. Did not obtain a degree \\
8. Extra-curricular activities & 1. Fair (C) \\
& 2. Very good (A) \\
& 1. Board member of a student committee \\
\hline
\end{tabular}

Note: Each vignette contained information on the vignette dimensions reported above. Vignettes were composed by randomly combining the above vignette levels. After crossing the vignette levels in all possible combinations (full factorial), a universe of all possible vignettes was created from which random samples of 18 vignettes were drawn without replacement and assigned to employers. Sub-samples of five vignettes were rated twice by each employer and are used for the empirical analyses discussed in this article. 


\section{Appendix B: Instructions given to respondents.}

You will now take part in the simulation of a selection process. Please indicate the job position you are most familiar with (i.e. the position for which you have selected the highest number of candidates or the position that is available in your organization):

\section{[ ] software engineer}

\section{[ ] IT business consultant}

Imagine you are required to hire a junior (job indicated above) for your organization. Please read the following job description carefully (one of the following job descriptions is shown).

\section{Software Engineer}

Work in a team on the design, development and maintenance of software applications and operating systems, translating clients' problems into customised and innovative technical solutions. Solve software-related issues in accordance with the demands of clients, including further maintenance and support of the software at the client's site. Report to the project leader on an on-going basis. Discuss functional requirements and update existing documentation for clients and suppliers.

\section{IT Business Consultant}

Work at the interface between Business and IT and show a thorough understanding of business processes. Analyse business processes together with clients, identify specific needs and translate these into feasible, innovative technical solutions. Give clients advice on complex issues including enterprise content management, business intelligence and custom systems development.

\section{Screening of résumés:}

In a moment you will compare résumés of candidates who have applied for a job as (job indicated above). In each résumé, demographic characteristics, educational background, job history, and extracurricular activities of the candidates are listed. You can find a more detailed description by moving the cursor over the résumé. Please indicate for each résumé the likelihood that you would hire the candidate.

A2. Résumé for a job as Software Engineer

\begin{tabular}{|l|l|}
\hline \multicolumn{2}{|c|}{ Candidate $\mathbf{1}$ of $\mathbf{2 3}$} \\
\hline Personal data & Female \\
\hline Gender & Yes \\
\hline Work experience & Yes \\
\hline Job History & University Master \\
\hline Internship & \\
\hline Level of education & Informatics \\
\hline Educational background & Graduated on time \\
\hline Field of study & A \\
\hline Duration of study & Yes \\
\hline Average exam result & $\begin{array}{l}\text { Board member of a students } \\
\text { committee }\end{array}$ \\
\hline
\end{tabular}

Please rate the profiles by moving the blue slider along the line. Please keep in mind that an answer of 0 equals the least likely and 100 the most likely option. Keep in mind that the answers for the three questions could differ for each candidate.

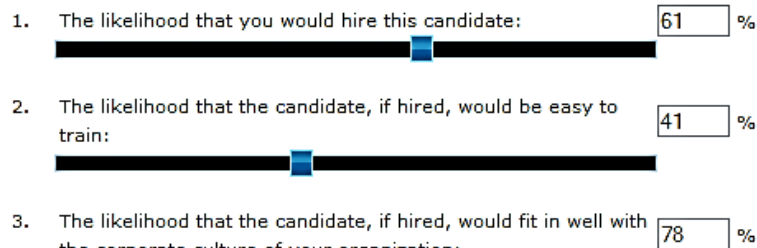
the corporate culture of your organization:

(First rating task: based on employers' ratings, a shortlist of five candidates is automatically generated) 


\section{Invitation to a job interview:}

Your screening of résumés generated the following shortlist of five candidates. Please rank these candidates in order of preference with regard to who you would invite to a job interview. Assign 1 to the candidate you would invite first, 2 to your second-best choice, and so on until 5.

(First ranking task: employers rank the five shortlisted profiles)

\section{Job interview and job offer:}

Additional information about each candidate became available during the job interview. Please consider the new information at the bottom of each résumé and again compare the candidates with one another. You can find a more detailed description by moving the cursor over the résumé.

In light of the information received, please re-rank the candidates according to the likelihood that you would hire them. Assign 1 to the candidate that you would prefer to hire, 2 to the second best, and so on until 5.

(Second ranking task: employers re-rank the five shortlisted candidates after receiving additional information as a filler)

\section{Experimental manipulation:}

Unfortunately, the five shortlisted candidates are no longer available, as they have found other jobs in the meantime. Consider a set of five new job candidates, who have been recruited informally through your network of professional and business contacts.

(Second rating task: five profiles, identical to the ones already rated in the first rating task, are shown to employers). 